\title{
Review on Aflatoxin and its Impacts on Livestock
}

\author{
Abebe Balina ${ }^{1}$, Abriham Kebede ${ }^{2 *}$ and Yobsan Tamiru ${ }^{2}$ \\ ${ }^{1}$ College of Veterinary Medicine, Mekelle University, Ethiopia \\ ${ }^{2}$ College of Medical and Health Science, Wollega University, Ethiopia
}

Submission: February 27, 2018; Published: May 31, 2018

*Corresponding author: Abriham Kebede; School of Veterinary Medicine, College of Medical and Health Science, Wollega University, P.0. Box, 395, Nekemte, Ethiopia, Tel: +251-917-095-077; Email: abrahamkebede2016@gmail.com

\begin{abstract}
Food contamination occurs when something is found in the food that should not be there. The main sources of contaminations are chemicals, physicals and microorganisms which include bacteria, virus, fungi, yeast and mold. The threat of aflatoxin contamination in food commodities and its association with health risk in both animals and humans is becoming an increasing concern over years. Aflatoxins are a group of mycotoxins mainly produced by Aspergillus flavus and Aspergillus parasiticus. These aflatoxins are divided into six major toxins according to their fluorescent properties under ultraviolet light and their chromatographic mobility. Both A. flavus and A. parasiticus produce aflatoxins B1 and B2 which produce blue fluorescence, while A. parasiticus produces aflatoxins G1 and G2 which have green fluorescence.

The four times hydrated aflatoxinB1and B2 is converted to aflatoxin M1 and M2 respectively. They present in the milk of lactating mammals which have consumed aflatoxin contaminated feed .Aflatoxin B1 is the most toxic and the most prevalent. There are great qualitative and quantitative differences in the aflatoxin producing abilities displayed by different isolates of each aflatoxigenic species. Lethal dose (LD50) values of these toxins range from 0.5 to $10 \mathrm{mg} / \mathrm{kg}$ according to the considered aflatoxin. It presence in commodities is unavoidable. To avoid their occurrence in the food chain management strategies requires. Their fore farmers, government agencies, food processors, scientists and others should be evolved in the system. Network should be done with community and create society awareness to control contamination of aflatoxin.

Keywords: Aflatoxin; Contamination; Lethal dose; Fungi; Community; Food processors; Scientists; Bacteria; Virus; Yeast; Mold; Carcinogen; Hepatotoxicity; Nephrotoxicity; Cyclopionic acid; kojic acid; Nitropropionic acid; Aspenoxin; Aflam; Aspergillic acid
\end{abstract}

\section{Introduction}

The contamination of food is worldwide problem. Food contamination occurs when something is found in the food that should not be there. The main sources of contaminations are chemicals, physicals and microorganisms which include bacteria, virus, fungi, yeast and mold. Fungi are unavoidable remarkable organisms that produce a wide range of natural product often called secondary metabolites. Mycotoxins are fungal metabolites that are currently considered to be the most dangerous and wide spread contaminant in food and animal feeds. Foodstuffs can be contaminated with mycotoxins before production, during storage, processing, transportation or marketing of the food products. High temperature, moisture content and water activity are among the predisposing factors that facilitate the production of mycotoxins in food [1]

Aflatoxins are a group of mycotoxins mainly produced by several fungus species in the genus Aspergillus. It includes $A$. flavus and A. parasiticus A. pseudotamarii, and A. nomis species. Among these species A. flavus and A. parasiticus are well known. These organisms invade crops and grow on foods during storage if temperature and humidity levels are favorable. The relative proportions and amounts of the various aflatoxins on food crops depend on the Aspergillus species present, pest infestation, growing and storage conditions, and other factors. Although these species have similar geographical ranges, A. parasiticus is less widely distributed and A. flavus is the most widely reported fungus in foodstuffs. Aflatoxins are metabolized in ruminants by the liver and excreted in the bile. The major aflatoxins produced in feed stuffs are B1, B2, G1, G2, m1 and m2. Both A. flavus and A. parasiticus produce aflatoxins $\mathrm{B} 1$ and $\mathrm{B} 2$, and $\mathrm{A}$. parasiticus also produces aflatoxins G1 and G2 [2].

Among these several type of aflatoxin strain, Aflatoxin B1 is the most potent mycotoxin (toxic substance produced by a mold). This type of toxin increases the apparent protein requirement of cattle and is a potent cancer causing agent (carcinogen). When significant amounts of aflatoxin B1 are consumed, the metabolite M1 appears in the milk within 12 hours. For all type of aflatoxin metabolites, the lethal dose (LD50) values range from 0.5 to $10 \mathrm{mg} / \mathrm{kg}$ according to the considered susceptibility of host. 
Aflatoxin contamination has been the most common cause of acute and chronic mycotoxicos is in animals and humans.

Hepatotoxicity, immunosuppression, carcinogenicity and nephrotoxicity are the major effects of aflatoxins. It has gained increasing attention due to their harmful effects on human and animal health and also due to the widespread presence of aflatoxigenic fungi in all the agricultural commodities under field and storage conditions [3]. Aflatoxin occurs worldwide. The recent estimates suggest that there are more than five billion people worldwide at risk of chronic exposure to aflatoxins. But it occurs more frequently in tropical countries because of high temperature, moisture, unseasonal rains. Most of the time aflatoxicos is a consequence of ingestion of contaminated feed with aflatoxins. That is continued to be problems of significant public health concern as long as people consumed contaminated animal products and considered as public health important. In the developing world seriously affect people's health and livelihoods, as freedom of choice in food is limited for a poor and food-insecure population $[4,5]$. Therefore, the objective of this paper is to highlight aflatoxins and their significance.

\section{Aflatoxin}

Aflatoxins are secondary fungal metabolites included in the class of mycotoxins. That produced by fungi genus Aspergillus species of. It produced during their growth under favorable conditions [6]. That contaminated agricultural commodities and can cause sickness or death in humans and animals [7].

There are several different types of aflatoxins strains. The most common naturally produced are B1, B2, G1, and G2 and two additional strains, M1 and M2 are the metabolic products of contaminated food or feed and are found in milk and other dairy products $[8,9]$. Aflatoxins designated by B1 and B2 show strong blue fluorescence under UV light, whereas the G1 and G2 forms show greenish yellow fluorescence. Aspergillus flavus produces aflatoxin B1 and B2.0thertoxic compounds produced by A. flavus are cyclopionic acid, kojic acid, nitropropionic acid, aspenoxin, aflam and aspergillic acid. A. parasiticus produces aflatoxin G1and G2 in addition to B1 and B2, but not cyclopionic acid [10].

\section{Properties}

Aflatoxins are produced by fungi in the genus Aspergillus that grow on grains and other agricultural crops. They exist as color less to pale-yellow crystals at room temperature. They are slightly soluble in water and hydrocarbons, soluble in methanol, acetone, and chloroform, and insoluble in non polar solvents. Aflatoxins are relatively unstable in light and air, particularly in polar solvents or when exposed to oxidizing agents, ultraviolet light or solutions with a PHbelow3orabove10. Aflatoxins decompose at their melting points, which are between $237^{\circ} \mathrm{C}$ (G1) and 299 ${ }^{\circ} \mathrm{C}$ (M1), but are not destroyed under normal cooking conditions. They can be completely destroyed by autoclaving in the presence of ammonia or by treatment with bleach. Physical and chemical properties of aflatoxins are listed in the following [11].
Physical properties of Aflatoxins: Aflatoxins are crystalline odorless solids when isolated and the color range from pale white to yellow. The melting points range from $268{ }^{\circ} \mathrm{C}$ for B1 down to $190{ }^{\circ} \mathrm{C}$ for $\mathrm{G} 2$ [12].

The optimal water activity for growth of A. flavus is high (about 0.99). The maximum is at least 0.998 whereas the minimum water activity for growth has not been defined. In general, production of toxins appears to be favoured by high water activity. Aspergillus flavus is reported to grow within the temperature range $10-43{ }^{\circ} \mathrm{C}$. The optimal growth rate occurs at a little above $30{ }^{\circ} \mathrm{C}$, reaching as much as $25 \mathrm{~mm}$ per day. The aflatoxins are produced by A. Flavus over the temperature range $15-37{ }^{\circ} \mathrm{C}$. It is not possible to specify an optimum temperature for the production of the toxins, although production between 20-30 ${ }^{\circ} \mathrm{C}$ is reported to be significantly greater than at higher and lower temperature [13].

Chemical properties of aflatoxins: Aflatoxins belong to the group of difuranocoumarins. The compounds are usually soluble in methanol, chloroform, acetone and acetonitrile which are slightly polar but insoluble in non-polar solvents. Aflatoxins react with alkaline solutions causing the hydrolysis of the lactones moiety. This hydrolysis is reversible since it has been shown that recyclization occurs following acidification of basic solution containing aflatoxin. At higher temperatures above $1000 \mathrm{C}$, ring opening followed by decarboxylation occurs and the reaction may proceed further, leading to the loss of methoxy group from the aromatic ring [14].

In the presence of mineral acids aflatoxins B1 and G1 are converted into aflatoxin B2A and G2A, due to acid catalyzed addition of hydroxyl group across the double bond in the furan ring. In the presence of acetic anhydride and hydrochloric acid, the reaction proceeds further to acetoxy derivative. Similar adducts of aflatoxin B1 and G1 are formed with formic acidthionyl chloride and trifluroacetic acid. Many oxidizing agents, including sodium hypochlorite, potassium permanganate, chlorine, hydrogen peroxide, ozone and sodium per borate, react with aflatoxin molecule in some way as indicated by the loss of fluorescence in ultraviolet light at 365nm [15].

Hydrogenation of aflatoxin B1 and G1 yields aflatoxins B1 and G1 respectively. Further reductions of aflatoxin B1 by three moles of hydrogen yields tetra hydroxyl aflatoxin. Reduction of aflatoxin B1 and B2 with sodium boro hydride yields aflatoxin $\mathrm{R}-\mathrm{B} 1$ and R-B2 respectively. These arise as a result of opening of the lactones ring followed by reductions of the acid group and reduction of the keto group in the cyclopentene ring [12].

\section{Intoxication}

Aflatoxins, like any other mycotoxins, are a subclass of substances which originated as a result of secondary metabolism of fungi. Unlike primary metabolites, these secondary metabolites are not essential for the growth of the fungi but have survival 
functions in nature. Genes required for aflatoxin production have persisted in fungi for more than 100 million years. Expression of secondary metabolite biosynthesis genes does not occur at high growth rates, which indicates that the synthesis of these metabolites occurs during growth repression. Aflatoxins induce DNA damage, negatively affect damage repair, and alter DNA base compositions of genes. Aflatoxins are associated with both toxicity and carcinogenicity in human and animal populations [16].

The usual routes for aflatoxins exposure are ingestion of aflatoxin contaminated foods and feeds [17]. Diet is the major way through which humans as well as animals are exposed to aflatoxins. Apart from this, exposure to aflatoxin can be through ingestion of contaminated milk M1 (metabolite of AflatoxinB1) [18]. The amount of this metabolite decides the species susceptibility as this can induce mutations [19]. Moreover species susceptibility to aflatoxin mainly depends on its liver detoxification systems, genetic makeup, age and other nutritional factors [20].

Wide variations of LD50 values had been obtained in animal species tested with simple doses of aflatoxins for most species. The LD50 values ranges from 0.5 to $10 \mathrm{mg} / \mathrm{kg}$ body weight. Animal species respond differently in their susceptibility to chronic and acute toxicity of aflatoxins. In each species the liver is the primary target of acute injury. Toxicity can be influenced by environmental factors, level of exposure and duration of exposure, age, health and nutritional status of diet. Metabolism plays a major role in determining the toxicity of aflatoxins B1 Studies show that this aflatoxin requires metabolic activation to exert its carcinogenic effect [21].

\section{Hepatotoxicity and Nephrotoxicity}

\section{Hepatic intoxication}

According to the World Health Organization (WHO). Hepatocellularcarcinoma in human is the third cause of cancer leading to deaths globally [22]. Aflatoxins metabolized by enzymes in the liver bind to proteins and causes acute toxicity). AflatoxinB1 is the most toxic of the aflatoxins and the strongest naturally occurring chemical liver carcinogen known immunity and nutritional processes [4].

Acute aflatoxicosis, associated with extremely high doses of aflatoxin, is characterized by hemorrhaging, acute liver damage, edema, and high mortality rates in humans. Acute aflatoxicosis is also related with sporadic outbreaks of the consumption of highly contaminated foods. Early symptoms of acute high level exposure to aflatoxin include diminished appetite, malaise, and low fever; later symptoms, which include vomiting, abdominal pain, and hepatitis, can signal potentially fatal liver failure [23].

\section{Nephrotoxicity}

Since, the role of the kidney as an organ of excretion reabsorption and general homeostasis make it the most subjected one for aflatoxicosis. The load of accumulated toxins within the tubules enhances mycotoxins nephrotoxicity. This nephrotoxicity is due to degenerative effects of glomerular basement membrane. The sever degenerative changes swelling of the cells even rapture of the membrane and cellular organelles in the tubular lumen as well as fibrocytic reaction and congestion of the vasculature in addition to glomerular reaction is manifested by atrophy of both visceral and paretalshirnked cells [24].

\section{Clinical signs}

Dairy and beef cattle are more susceptible to aflatoxicosis than the other species. Young animals of all species are more susceptible to the effects of aflatoxins than mature animals. Pregnant and growing animals are less susceptible than young animals but more susceptible than nature animals. Toxicity due to aflatoxins, under natural conditions, is usually sub acute or chronic, depending on the level of exposure. Occasionally, acute cases are also seen. In general affected animals show reduced growth rate, weight loss, immune suppression, icterus, hemorrhagic enteritis, reduced performance, and ultimately death [25].

\section{Diagnosis}

Aflatoxicosis in milking cows is readily evident from milk samples. However, diagnosis in nonlactating cattle is more difficult because of the variation in clinical signs, gross pathology, and presence of other diseases due to suppression of the immune system. More than one mold or toxin can further complicate diagnosis as well. By the time overt symptoms are noticed, the prognosis is poor. Aflatoxins have usually been detected by their photo physical properties, such as by absorption and emission spectra. For instance, aflatoxins show characteristic absorption at $360 \mathrm{~nm}$, which is the absorption maximum of the aflatoxin ring [26].

Different methods of detection and quantification of aflatoxins are: ELISA, electrochemical immune sensors, chromatography and fluorescence. ELISA is widespread technique. Competitive direct enzyme linked immune sorbent assay test is one of the most common tests conducted in immune biochemistry that allows the user to obtain exact concentration in parts per billion. But it has the disadvantage of requiring well equipped laboratories, well trained professional, harmful solvents and several hours to complete an assay [27].

The detection and quantification of aflatoxins by using electrochemical immune sensor has proven to be efficient, easy to use and able to detect very low levels of aflatoxin. Fluorescence detection is a very good alternative to the conventional techniques. It has a very high sensitivity. But it is inexpensive [28].

Rapid detection techniques are optical fiber, electrochemical transduction, low injection monitoring and biosensors. Most of these still present a lack of applications because of their practical 
inconveniences except biosensors. The biosensors have been designed to overcome the drawbacks that the common tools employed to detect and quantify aflatoxins presents. Apparently then measurement of aflatoxins in the future tends to be the combination of optical, immunochemical and fluorescence techniques [29].

\section{Epidemiology}

Aflatoxins can affect a wide range of commodities including cereals, oilseeds, spices, and tree nuts as well as milk, meat, and dried fruit. Reports from different part of the world indicated incidence of aflatoxins vary from 40 to $92 \%$. Especially developing countries located in the tropical regions have greatest risk. Their climate is favourable to growth of aflatoxin. Where dietary food stuffs and Staple food source commodities is highly contaminated with aflatoxins [30]. Aflatoxicosis is the most important food borne mycotoxins. It has greatest significance in tropical developing countries [31,32].

Epidemiological studies carried out in several parts of Africa and Asia indicates a correlation between exposure to aflatoxins and primary liver cancer [33]. Besides several epidemiologic investigations is shown that increased aflatoxin ingestion correlates with increased risk of hepatocellular carcinoma in humans [34].

Aspergillus flavus and aflatoxin forms sclerotia which allow it to survive in soil for extended periods of time [35]. The sclerotia are the principal sources of primary inoculum. They are also found in foodstuffs and are not destroyed by normal industrial processing or cooking since they are heat-stable. Conditions such as high temperatures and moisture, unseasonal rains during harvest and flash floods lead to fungal proliferation and production of mycotoxins [36]. Poor harvesting practices, improper storage and less than optimal conditions during transportation, marketing and processing can also contribute fungal growth and increase the risk of mycotoxins production [37]. Some of their metabolites are still toxic and may be involved in human diseases. The toxic effects of aflatoxins on organs like liver, kidney and mainly their carcinogenic effects are mostly known causes of morbidity and mortality [38].

\section{Economic and public health significance}

\section{Economic significance}

The economic consequences of aflatoxicosis are the major areas of concern. Aflatoxins have negative impact on human health, animal productivity and trade. Generally, when susceptible animals are fed contaminated feeds it results in reduced growth rates, illness, and death; moreover, their meat and milk may contain toxic biotransformation products. Livestock owners often take farmers and feed companies to court legal battles can involve considerable amounts of money [39]. The direct economic impact of aflatoxin contamination in crops results mainly from a reduction in marketable by rejection of products from the international market and losses incurred from livestock disease, consequential morbidity and mortality which leads to volume and value loss in the national markets which is huge economic loss [37].

Recommended sanitary and phytosanitary standards set for aflatoxins adversely affect grain trade in developing countries, specifically in the international market, products that do not meet the aflatoxin standards are either rejected at the border, rejected in channels of distribution, assigned a reduced price [40].

The crops contaminated with high levels of aflatoxins are sometimes diverted to animal feed, which resulting in reduced growth rates and illness of animals consuming toxic contaminated feeds. Many countries have established regulations to limit exposure to aflatoxin, typically expressed in parts per billion (ppb). These regulations can result in foregone trade revenues arising from increased cost of meeting the standards including cost of testing, rejection of shipments and even eventual loss of admissibility into foreign markets [41].

Toxigenic fungal pathogens are important constraints to the production of the crop, affecting the quality of the seeds through spoilage, however, aflatoxin contamination is the most important quality problem in Ethiopia with serious health consequences for human and livestock for example groundnut plays an important role as a food as well as a cash crop in Ethiopia. Currently the crop is becoming one of the high value crops that are growing in the dry land areas of the Tigray region, Northern Ethiopia, but the groundnut production highly attack by aflatoxicosis [36].

\section{Public health significance}

The human health consequences of acute aflatoxicosis alone range from death to exacerbated malnutrition, devastating to the affected populations. When lactating animals are fed aflatoxin contaminated feed, they excrete aflatoxin metabolites into the milk. The aflatoxins are capable of causing aflatoxicosis in consumers of milk. This is why government regulations specify that milk must be free of aflatoxin. However, action is not taken until the aflatoxin level exceeds $0.5 \mathrm{ppb}$ in market milk, the level below which there is no hazard for the consuming public. "Action levels" for livestock represent the level of contamination at which the feed may be injurious to their health or result in contamination of milk, meat or eggs [42].

\section{Prevention, Control and Treatment}

\section{Prevention}

Aflatoxicosis can be prevented by feeding rations free of aflatoxin. Preventing aflatoxin contamination requires ongoing and thorough sampling and testing program. It requires purchasing feed from reputable persons and companies experienced in aflatoxin prevention and who have a proven record of properly monitoring their feed products. A reliable feed company will also carry insurance to cover misfortunes 
with aflatoxins or other problems. A good deal on feed prices can be the most expensive buy a dairy farmer ever makes if it proves to contain aflatoxin. Storing feed at proper moisture levels and developing a systematic inspection and clean-up program to keep bins, delivery trucks and other equipment free of adhering or caked feed ingredients are also the most important options. Minimizing dust accumulation in milling and mixing areas and treating grains contaminated with aflatoxins by ammonia have also been successfully inclusive method of preventing the disease but it is expensive and dangerous to do [43].

\section{Control and treatment}

The presence and growth of Aspergillus on pre-harvested crops is dependent on the environment. Agricultural practices including proper farm system and pest management can reduce aflatoxin contamination. Controlling or reducing infection by regulating the factors that increase the risk of aflatoxin contamination in the field contributes extensively in managing aflatoxin. Management practices that reduce the incidence of aflatoxin contamination in the field include timely planting, maintaining optimal plant densities, proper plant nutrition, avoiding drought stress, controlling other plant pathogens, weeds and insect pests and proper harvesting [44]. Another potential means for aflatoxin control is the biocontrol of fungal growth in the field. Numerous organisms have been tested for biological control of aflatoxin contamination including bacteria, yeasts, and non-toxigenic (toxigenic) strains of the causal organisms of which only toxigenic strains have reached the commercial stage [45]. Soil testing, field crop rotation, antifungal chemical treatments (for example, proprionic and acetic acids), and adequate insect and weed prevention. Harvesting strategies include use of functional harvesting equipment, clean and dry collection/transportation equipment, and appropriate harvesting conditions (low moisture and full maturity). Postharvest measures include use of drying as dictated by moisture content of the harvested grain, appropriate storage conditions, and use of transport vehicles that are dry and free of visible fungal growth $[46,47]$.

Sorting out of physically damaged and infected grains from the intact commodity can result in $40-80 \%$ reduction in aflatoxin levels. The advantage of this method is that it reduces toxin concentrations to safe levels without the production of toxin degradation products or any reduction in the nutritional value of the food. This could be done manually. Market practices such as grading have also been shown to reduce levels of aflatoxin [48]. Clearing the remains of previous harvests and destroying infested crop residues are basic sanitary measures that are also effective against storage deterioration. Cleaning of stores before loading in the new harvests was correlated with reduction in aflatoxin levels. Wild hosts, which constitute a major source of infestation for storage pests, should also be removed from the vicinity of stores. These improved postharvest technologies have been used successfully to reduce the blood aflatoxin [49].
Aflatoxin regulatory programs are already in place in most countries to the export side these regulatory programs are strictly enforced to protect the export market of agricultural commodities, otherwise the importing countries would reject the commodities resulting in a loss of valuable foreign exchange earnings. Domestic regulatory measures on aflatoxin have received very little attention and are enforced, with no incentives given for the aflatoxin free produce and no heavy penalty on the violators of aflatoxin regulations.

To reduce the losses due to aflatoxin contamination risks must be solved through using sanitary measures during pre harvest, harvest postharvest handling of food and feeds of animals. Multi-sectoral approaches programs are required at all levels to control aflatoxin contamination and improve the quality of product to security and health assessments of communities. Aflatoxin control program will include complementary components such as relevant information standards regulations policy to distribute safe and high quality food to fulfil consumer's demands [50].

Many chemical preservatives have been used for the control of Aspergillus food contamination such as fungicides, herbicides and insecticides for healthier plants that resist fungus [51]. The widespread use of chemical preservative has significant drawbacks including increased cost, handling hazards, concern about residues of pesticide on food and threat to human health and environment. There is no specific antidote for toxicity of aflatoxins. However; timely administration of l-methionine $(200 \mathrm{mg} / \mathrm{kg})$ and sodium thiosulfate $(50 \mathrm{mg} / \mathrm{kg})$ at eight-hour intervals is proven to be of therapeutic value. Supplementation with increased levels of protein, vitamins and antioxidants can also be rewarding [52].

\section{Conclusion and Recommendations}

Food has always played an extra-ordinarily vital role in the growth or fall of a nation. Consumption of unsafe contaminated food leads to food borne diseases which cause considerable morbidity and mortality. Aflatoxin contamination of foods and feeds is a serious worldwide problem resulting either from improper storage of commodities or pre harvest contamination. So its contamination is a global food security issue, especially in developing countries as limite freedom of choicing food.

It is limited for a poor and food insecure population. Its presence in food products and animal feeds is an important problem concerned with food and feed safety. Significant economic losses are associated with their impact ton human and animal health. The contamination in food commodities threat does follow the rules of dosage to response and association with health risks in both animals and humans. They also have greater attention than any other mycotoxins because of their potent acute toxicological and carcinogenic effect in susceptible animals and humans, as well as the economic impact drive directly 
from crops, livestock and their product losses, and indirectly from the cost of regulatory programs designed to reduce risks of animals and humans health. Lacks of sanitary measures on food commodities usually contaminated with aflatoxins mould growth is an unavoidable and may pass through manufactures and cooking processes [53,54].

Based on the above conclusion, the following recommendations are forwarded:

a. Natural contaminants of food chain with aflatoxin should be reduced by using sanitary measures and a multiface awareness approach.

b. Primary products such as cereals and animal products should be screened routinely for aflatoxins.

\section{Acknowledgement}

We would also like to express our gratitude to Mekelle University and Wollega University, College of Medical and health science, School of Veterinary Medicine Staff of School of Veterinary Medicine for inspiration and moral support that enabled to prepare this Seminar paper.

\section{Authors' Contributions}

"Abriham kebede Deresa has contributed to design the title and reviewing the manuscript to be ready for publication". "Abebe Belina and Yobsan Tamiru have participated in the data collection from different pdf and compile the manuscript. All authors read and approved the final manuscript".

\section{References}

1. Wageh D, Mayumi I, Shoata M, Yoshinor I (2014) Cellular interactions and metabolism of aflatoxin. Journal of Pharmacology 65(2): 163-92.

2. Ramesh V, Siruguri V (2003) Food safety in food security and food trade Mycotoxin Food Safety Risk in Developing Countries. Journal of Food Microbiology 7: 219-225.

3. Shephard S (2008) Risk assessment of aflatoxins in food in Africa food Additives and contaminants control exposure and Risk Assessment. Journal of Food Additive 25(10): 1246-1256.

4. Williams H, Phillips D, Jolly E, Stiles K, Jolly M, et al. (2004) Human aflatoxicos is in developing countries a review of toxicology exposure potential Health consequences and interventions. Am J of Clin Nutr 80(5): 1106-1122.

5. World Health Organization (WHO) (2005) Public health Strategies for Preventing Aflatoxin exposure. workgroup report for the international Mycotoxin Workshop p. 1-26.

6. Klich A (2007) Aspergillus flavus the major producer of aflatoxin, Mol Plant Pathol 8(6): 713-22.

7. Ellis W, Oldha H, Simpson B, Smith J (1991) Aflatoxin in food: occurrence, biosynthesis, effects on organisms detection, and methods of control. Crit Rev Food Sci Nutr 30(4): 403-439.

8. Lopez C, Bulacio L, Ramadan S, Ramos L (2002) Rodriguez AflatoxinB1content in patients with hepatic diseases. Medicine 62(4): 313-316.

9. Tseng C (1994) Recent aspects of aflatoxin Research in Taiwan. Journal of Toxicological Review 13: 229-241.
10. Yu J (2004) Genetics and Biochemistry of mycotoxin synthesis. Journal of Fungal Biotechnology 21: 343-361.

11. International Agencies for Research on Cancer (IARC) (1993) Monographs on the Evaluation of Carcinogenic Risk of Chemicals to Humans. France 56: 245-395.

12. Waliyar F, Reddy S (2003) Immunochemical methods of analysis. International Crops Research Institute for the Semi-Arid Tropics (ICRISAT) strategy 3: 79-102.

13. Pitt J, Miscamble B (1995) Water relations of Aspergillus flavus and closely Related species. Food Protection 58: 86-90.

14. Scott L, King W, Richard L, Greer T (1993) Analytical scale super critical fluid extraction of aflatoxin B1 from field inoculated corn. J of agric and Food chem 41(6): $910-913$.

15. Healthcote G, Hibert R (2005) Aflatoxins: Chemicaland Biological aspects. Journal of Food Science 5: 30-130.

16. Carry J, Ehrlich K (2006) Aflatoxigenicity in Aspergillus. Molecular genetics 162: 167-177.

17. Bennett J, Klich M (2003) Mycotoxins. Clinical Microbiology Review 16: 497-516.

18. Eaton L, Gallhager E (1994) Mechanism of aflatoxin Carcinogenisis. Annu Rev Pharmacol Toxicol 34: 135-172.

19. Smela M, Sophie S, Curier E, Bailey A, John M (2001) The chemistry and biology of aflatoxinB1.Carcinogenesis 22(4): 535-545.

20. Howard S, David L, Ram D (1990) Species susceptibility to Aflatoxin B1 carcinogenesis.Cancer Research 4: 50-62.

21. Pomeranz Y (1992) Biochemical Functional and Nutritive Changes During Storage: Storage of Cereal grains and their products. $\left(4^{\text {th }}\right.$ edn), Florida, p. 55-141.

22. World Health Organization (WHO) (2008) World Health Statistics Geneva.

23. Barret R (2005) Liver cancer and Aflatoxin Outbreak. Environ Health Perspect 113 (12): 837-838.

24. Evelyn 0, Brien R, Daniel R, Dietrich P (2004) Mycotoxins. Affecting the Kidney Toxicology of Kidney 25(11): 895-936.

25. Boatell R, Asquith G, Edds C, Aller W (1993) Acute experimentally induced aflatoxicosis in the weanling pony. American Journal of Veterinary Research 44: 2110-2114.

26. Korde A, Banerjee S, Pillai M, Venkatesh M (2001) Preparation and evaluation of AflatoxinB1.Journal of Radioanal Nuclear Chemistry 250(2): 231-237.

27. Dallasta C, Ingletto G, Corradini R, Galaverna G, Marchelli R (2003) Fluorescence enhancement of aflatoxins using native and substituted cyclodextrins. Journal of Inclusion Phenomena and Macrocyclic Chemistry 45(3): 257-263.

28. Cavaliere C, Foglia P, Pastorini E, Samperi R, Lagana A (2006) Liquid chromatography/tandem mass spectrometric confirmatory method for determining aflatoxin M1 in cow milk:: Comparison between electrospray and atmospheric pressure photoionization sources. Journal Chromatogr A 1101(1-2): 69-78.

29. Carlson M, Bargeron C, Benson R, Fraser A, Phillips T, et al. (2000) An automated, handheld biosensor for aflatoxin. Biosensors and Bioelectronics, 14(10-11): 841-848.

30. Strosnider H, Baumgartner E, Banziger M, Bhat V et al. (2006) Workgroup report public Health strategies for reducing aflatoxin exposure in developing countries. Environ Health Perspect 114(12):1898-1903. 
31. Kumar V, Basu S, Rajendran T (2008) Mycotoxin Research and Mycoflora in some commercially important agricultural commodities. Crop Protection 27(6): 891-905.

32. World Health Organization (2006) Mycotoxins in African foods: Implications to food safety and Health AFRO Food Safety Newsletter World Health Organization Food Safety Issue.

33. Diaz G, Rojas Y, Perilla S (2001) Occurrence of Aflatoxins in selected Colombian foods. Mycotoxin Res 17(1): 15-20.

34. Bhatti B, Sardar R, Talat T (2001) Estimation of aflatoxin B1 in feed ingredients and compound poultry feeds. Pakistan Veterinary Journal 21: $57-60$

35. Scheidegger K, Payne G (2003) Unlocking the secrets behind secondary metabolism: A Review of Aspergillus flavus from pathogenicity to functional genomics. Journal of Toxicology 22: 423-459.

36. Bhat R, Vasanthi S (2003) Mycotoxin food safety risks in developing countries. Agriculture and Environment Focus 10: 1-2.

37. Wagacha J, Muthomi J (2008) Mycotoxin problem in Africa current status implications to food safety and Health and possible management strategies. Int J of Food Microbiol 124(1): 1-12.

38. Smith J, Solomon G, Lewis C, Anderson J (2001) Mycotoxins in human Nutrition and Health. European Commission Publication 10: 670-700.

39. Pier A, Richard L, Cysewski S (1990) Implications of mycotoxins in animal Disease. Journalof American Veterinary Medicine Association 176: 719-724

40. Gebrehiwet Y, Kirsten J, Qangweni W (2007) Quantifying the trade effect of sanitary and phytosanitary regulations of Organization for Economic Cooperation and Development (OECD) countries on South African food exports. Agrekon 46(1): 23-38.

41. Cooper J, Dobson H (2007) The benefits of pesticides to mankind and the Environment crop protection. 23: 1337-1348.
42. Lopez R, Park L, Phillips D (2012) Integrated mycotoxin management systems. Journal of Dairy Science: 95: 5901-5908.

43. Ellen R (2010) Aflatoxins and Dairy Cattle. Educational programs of the Texas Agri Life Extension Service 3: 1-4.

44. Bruns A (2003) Controlling Aflatoxin and fumonisin in maize by crop management. Journal of Toxicology Review 22(2,3): 153-173.

45. Yin Y, Jiang H, Ma H (2008) Biological control of aflatoxin contamination of crops J of Zhejiang Univ 9(10): 787-792.

46. Codex Alimentarius Commission (CAC) (2003) Code of practice for the prevention and reduction of mycotoxin contamination incereals.

47. Quillien J (2002) Mycotoxins Institution of National Researcher Agronomique.

48. Mutegi C, Hendriks S, Jones R, Okello J, Ngugi H (2007) Role of collective action and handling practices on aflatoxin contamination of ground nuts. Proceedings of the African Crop Science conference 8: 1779-1782.

49. Hell KB, Yopadhyay R, Cardwell K (2008) Pre and postharvest management of aflatoxin in maize. Wallingford, UK, pp. 210-219.

50. Hassan A, Aziz N (1998) Influence of moisture content and storage temperature on the production o faflatoxins by A.flavusinmaize after exposure to Gamma radiation. Journal of food safety 3: 159-171.

51. Maier E, Fuch D, Jenny M, Kurz K, Schennach H (2010) Food preservatives. Food Chemistry and Toxicology 48: 1950-1956.

52. Nollet L, Rathore H (2010) Handbook of Pesticides Methods. Pesticide Residues Analysis, USA pp. 25-30.

53. Groopman D, Kensler W (2005) Role of metabolism and viruses in a flatoxin-induced liver cancer. Toxicology Applied Pharmacology 206(2): 131-137.

54. Luchese R, Whitaker T (2003) Detecting Mycotoxins in Agricultural Commodities Molecular Biotechnology 23(1): 61- 71

\section{Your next submission with Juniper Publishers will reach you the below assets}

- Quality Editorial service

- Swift Peer Review

- Reprints availability

- E-prints Service

- Manuscript Podcast for convenient understanding

- Global attainment for your research

- Manuscript accessibility in different formats

( Pdf, E-pub, Full Text, Audio)

- Unceasing customer service

Track the below URL for one-step submission https://juniperpublishers.com/online-submission.php 